\title{
Management of Calcinosis Associated with Systemic Sclerosis
}

\author{
Antonia Valenzuela, $M D, M S^{1}$ \\ Lorinda Chung, $M D, M S^{2, *}$
}

\author{
Address \\ ${ }^{1}$ Division of Immunology and Rheumatology, Stanford University School of Med- \\ icine, 1000 Welch Road, Suite 203 MC 5755, Palo Alto, CA, 94304, USA \\ *,2Division of Immunology and Rheumatology and Department of Dermatology, \\ Stanford University School of Medicine, 1000 Welch Road, Suite 203 MC 5755, \\ Palo Alto, CA, 94304, USA \\ Email: shauwei@stanford.edu
}

Published online: 2 February 2016

(C) Springer International Publishing AG (outside the USA) 2016

This article is part of the Topical Collection on Scleroderma

Keywords Calcinosis cutis · Calcifications · Calcium · Systemic sclerosis · Ulcerations · Treatment

\section{Opinion statement}

Calcinosis is a common and debilitating manifestation of systemic sclerosis (SSc). It most commonly involves the hands, particularly the fingers, and it is often associated with pain, recurrent episodes of local inflammation, and functional impairment. We recommend preventative measures such as smoking cessation, avoidance of cold, stress, and trauma in all patients, along with aggressive treatment of Raynaud phenomenon and digital ulcers. If pain and inflammation are present, we recommend acetaminophen and/or non-steroidal anti-inflammatory agents; however, narcotics may be necessary in some cases. Corticosteroid injections with $20 \mathrm{mg} / \mathrm{mL}$ of triamcinolone acetonide suspension may also be effective in reducing secondary inflammation from calcinosis, as well as minocycline 50 or $100 \mathrm{mg} /$ day in cyclic long-term use, and colchicine $1 \mathrm{mg} /$ day orally. In case of infection, we add antibiotics with appropriate coverage for streptococci and staphylococci, such as cephalexin, dicloxacillin or clindamycin. The pharmacological treatment aimed to reduce calcinosis is challenging given that no therapies have consistently been found to be effective and no randomized controlled trials have been completed to date. We refer a significant proportion of patients with large, localized, and symptomatic lesions for surgical excision. Randomized controlled trials using novel outcome measures are necessary to evaluate the efficacy of proposed and emerging therapies. 


\section{Introduction}

Calcinosis cutis is the deposition of calcium in the skin and subcutaneous tissues [1•] (Fig. 1). It is associated with autoimmune connective tissue diseases (ACTD) including systemic sclerosis (SSc), dermatomyositis (DM), mixed connective tissue diseases (MCTD), and more rarely, systemic lupus erythematosus (SLE) [2•].

Calcinosis in SSc presents as subcutaneous nodules of variable size and shape, typically at sites of recurrent microtrauma. One quarter of patients with SSc have calcinosis at some time during their illness [3], on average more than 7.5 years after the onset of SSc. [2 $\bullet$ The most frequent body sites involved in SSc are the hands (particularly the palmar side of the distal phalanges) and feet. Other common areas that can be affected include the elbows and knees, arms and legs, trunk, and face, in order of frequency $[2 \bullet, 4 \bullet \bullet, 5 \bullet]$. Small single-center studies have related SSc-calcinosis with several clinical features including male gender [6], digital ulcers [6, 7], digital tip pitting scars [7], acro-osteolysis [8•], telangiectasias [9], anti-centromere antibody $[9,10]$, and anti-PM/Scl antibody [11]. A recent retrospective multi-center international cohort study of 5218 patients with SSc, where 1290 patients $(24.7 \%)$ had calcinosis, confirmed a strong association of calcinosis with digital ulcers (odds ratio (OR) 3.7, $95 \%$ confidence interval (CI) 2.6-5.3, $p<0.0001)$ and found a novel association with osteoporosis (OR 3.9, $95 \%$ CI 2.1-7.4, $p<0.0001$ ) [3].

Calcium deposits are made of calcium hydroxyapatite crystals and contain calcium, hydroxides, and phosphates. Although the detailed pathophysiology of calcinosis cutis remains poorly understood, [2•] two general mechanisms of calcification in soft tissues-metastatic and dystrophic calcification-have been described [12•]. Metastatic calcification is the deposition of calcium

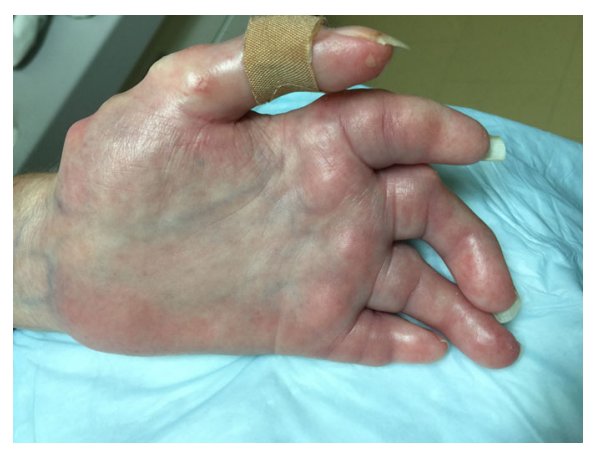

Fig. 1. Calcinosis of the fingers. in normal cutaneous or subcutaneous tissue in the presence of elevated levels of serum calcium and/or phosphate $[13,14]$. Dystrophic calcification-the most common presentation of calcinosis cutis occurring in association with SSc [14] -is the deposition of calcified material in diseased tissues as a result of an insult associated with normal serum calcium and phosphate levels [13]. Chronic inflammation and vascular hypoxia are thought to play a role in the tissue damage that serves as a nidus for dystrophic calcification $[1 \bullet, 15 \bullet]$. The role of activated macrophages and inflammation is supported by elevated levels of interleukin (IL)-1 in the serum, and the presence of IL-6, IL-1 $\beta$, and tumor necrosis factor (TNF)- $\alpha$ in the "milk of calcium" (calcium-laden fluid collections) found in patients with juvenile DM [16]. Regarding vascular hypoxia, Davies et al. demonstrated increased expression of the hypoxia-associated glucose transporter molecule (GLUT-1) by immunohistochemistry in skin biopsies of patients with SSc-associated calcinosis. [17] Similarly, the same group evaluated the expression of recognized markers of oxidative stress, the advanced glycation/lipoperoxidation end products (AGEs) and their receptor (RAGE) and concluded that it was greater in the dermis of patients with SSc, especially in those with calcinosis, when compared to healthy controls [18].

Calcinosis is often clearly palpable or visible on physical examination; however if not, imaging studies may be helpful to confirm the diagnosis. Plain radiography is very sensitive in detecting calcinosis and is recommended as the initial imaging evaluation in patients with ACTD, showing multiple non-specific morphological patterns of calcification (nodular, sheet-like, reticular, amorphous, linear) [5•]. The recent development of a novel radiographic scoring system that evaluates the area coverage, density, and anatomic location of calcinosis affecting the hands in patients with SSc, with excellent reliability (inter-rater reliability intraclass correlation $($ ICC) $=0.89$, $95 \%$ CI 0.86-0.92, and intra-rater reliability ICC $=0.89$, $95 \%$ CI $0.8-0.97$ ) should increase the use of plain radiography in routine patient care and clinical trials [19•]. Other imaging techniques such as conventional computed tomography (CT) scans and magnetic resonance imaging (MRI) may be particularly useful in the assessment of lesions involving the trunk, or plaque-like lesions [20•]. Small studies have evaluated the efficacy of ultrasonography (US), multidetector computed tomography (MDCT), and dual-energy computed tomography (DECT) in detecting calcinosis with adequate sensitivity 
$[20 \bullet, 21,22,23 \bullet]$. Further studies are necessary to determine whether US, MDCT, and/or DECT might be more useful in the assessment and measurement of calcinosis burden than plain radiography.

Common complications of calcinosis are ulceration at the site of lesions, infection, pain, impaired function, and compression of nerves. In one retrospective study of
78 patients from the Mayo Clinic, the largest cohort of patients with calcinosis in ACTD studied so far, 43 patients $(55 \%)$ had ulcer formation in the context of calcinosis cutis, and 54 patients (69\%) had pain associ-

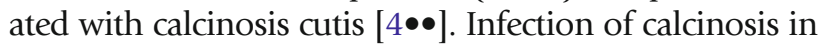
SSc is underreported, but may also cause pain, and potentially, septicemia [24].

\section{Treatment of calcinosis}

\section{General measures}

The scarcity of effective options described in the literature makes the treatment of calcinosis a major clinical challenge (Table 1). Given its relation to hypoxia, general measures to improve blood flow to the extremities, such as avoiding trauma, smoking, stress, and cold exposure, are of crucial importance. Likewise, the medical treatment of Raynaud phenomenon and digital ulcers may play a role in prevention and treatment of calcinosis. Supportive therapies such as pain and anti-inflammatory medications, treatment of infection, and wound care are also a key. If pain is present, acetaminophen and non-steroidal antiinflammatory agents can help; however, narcotics may be necessary for

Table 1. Treatment of calcinosis in systemic sclerosis

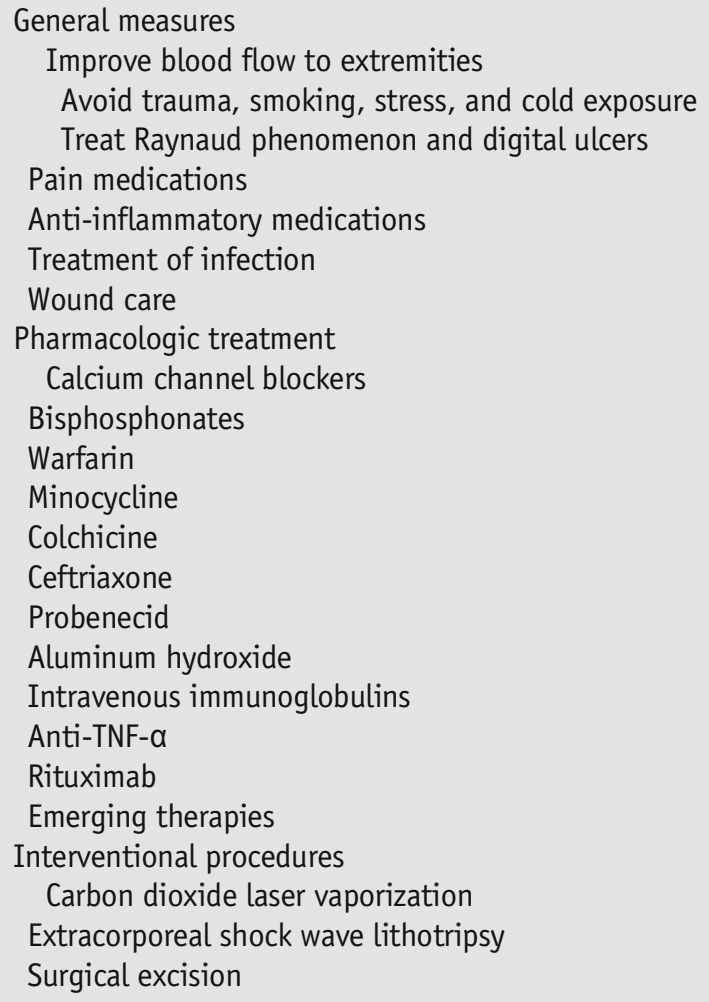


adequate pain control. Corticosteroid injections are well tolerated and palliative and may be effective in reducing secondary inflammation from calcinosis. In one published case of a patient with SSc and calcinosis, injection of the margins of the lesion with $20 \mathrm{mg} / \mathrm{mL}$ of triamcinolone acetonide suspension at 4- to 8-week intervals resulted in healing at 12 months [25]. An antibiotic should be prescribed if there is suspicion of superinfection of a calcinotic lesion with clinical features as spreading redness or thick green/yellow discharge. The most frequent organism identified in cultures has been Staphylococcus aureus $[24,26,27]$; therefore, appropriate empirical treatment with oral antibiotics with good coverage for streptococci and staphylococci, such as cephalexin, dicloxacillin, or clindamycin, are recommended. If calcinosis becomes ulcerated, hydrocolloid membranes such as Duoderm may be useful. Duoderm is a polyurethane film coated with a strong adhesive that protects skin from bacteria and serves as a barrier against further injury. We recommend cleaning the area over the ulcer with hydrogen peroxide $3 \%$ or an antibacterial soap, drying, and covering with antibacterial ointment. Duoderm should be cut approximately $1 / 2$ to $1 \mathrm{in}$. beyond the wound's margin and applied to the wound after peeling off the adhesive. A tape may be used around the edges of the dressing to aid in keeping it in place. The Duoderm dressing should be changed and cleaned every third day, or sooner if the dressing is oozing a lot of fluid.

Pharmacological treatment

Several pharmacologic therapies aimed at reducing calcinosis, as monotherapy or in combination, have been successful in isolated cases, but none seems to be consistently effective, and the majority of evidence comes from case reports, small case series, and small open-label studies. Furthermore, these agents have not received regulatory approval, since until recently, there have not been any validated outcome measures to study them in randomized clinical trials, and their clinical impact requires a prolonged observation period.

\section{Calcium channel blockers}

Calcium channel blockers (CCB) alter the formation and crystallization of the calcium nidus by reducing the intracellular calcium influx in the affected tissues and local macrophages. Diltiazem is the CCB most frequently used for the

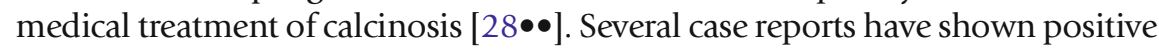
results with diltiazem from 240 to $480 \mathrm{mg} /$ day for 1 to 12 years for calcinosis in SSc patients. [29-31] In the Mayo Clinic study, diltiazem was effective in 9 out

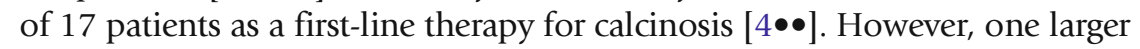
retrospective study of 23 patients with SSc and calcinosis on hand radiographs, where 12 were treated with $180 \mathrm{mg} /$ day of diltiazem, reported a clinically insignificant regression of lesions in three patients [9]. The use of other CCB has been less frequently reported [ $28 \bullet \bullet]$. In the study by Palmieri et al., one patient who did not tolerate diltiazem received verapamil without effective response [29]. In the Mayo Clinic study, one patient who was treated with amlodipine improved $[4 \bullet \bullet$. Potential side effects of calcium channel blockers are arterial 
hypotension, lower extremity edema, and headache. Despite this conflicting evidence, CCB have been proposed as the first choice treatment for calcinosis in ACTD by some authors $[4 \bullet \bullet, 28 \bullet \bullet]$.

\section{Bisphosphonates}

Bisphosphonates may be useful in reversing the calcification process by inhibiting macrophage proinflammatory cytokine production and reducing calcium turnover. The association between calcinosis and osteoporosis also suggests that these agents may have a role in the treatment of calcinosis. Conflicting reports regarding the effect of bisphosphonates on calcinosis have been published. A report of six patients with dystrophic calcinosis associated with DM or SSc treated with etidronate for a mean of 10 months demonstrated little success, and moreover showed that all three patients with SSc had clinical and radiologic progression of calcinosis lesions. [32]. However, another SSc patient with extensive calcinosis seen on clinical and radiological examination was treated with etidronate for 1 year and had functional improvement and partial regression of lesions [33]. A more recent case report described clinical and radiological resolution of calcinosis in one limited cutaneous SSc (lcSSc) patient after 6 months of treatment with risedronate for glucocorticoid-induced osteoporosis [34]. Intravenous infusion of pamidronate has been reported to be effective for calcinosis in several case reports/series mostly in DM patients [28••]. Gastrointestinal (GI) side effects such as acid reflux, esophagitis, and esophageal ulceration are the primary concern for patients and may be prevented by taking the medication on an empty stomach first thing in the morning with at least $8 \mathrm{oz}$ of water and avoiding food for half an hour. Given the paucity of evidence, the efficacy of bisphosphonates in calcinosis treatment remains unclear.

\section{Warfarin}

By antagonizing vitamin $\mathrm{K}$, warfarin inhibits the production of gammacarboxyglutamic acid, which has calcium and phospholipid-binding properties, and has been found to be increased in patients with calcinosis [15•]. Although several studies suggest that warfarin may be effective for small calcified deposits [35] , evidence supporting the use of warfarin in calcinosis is conflicting, and its use is not widely accepted. In a double-blind placebo-controlled study of 7 patients with SSc or DM and evidence of substantial and multiple subcutaneous calcifications, three patients received warfarin $1 \mathrm{mg} /$ day for 18 months and four patients received placebo. Two patients in the treatment arm showed decreased extra-skeletal uptake on whole-body bone scintigraphy with injection of technetium 99m-diphosphonate compared with none in the placebo arm. [36]. A case series of three patients with SSc found that two patients had complete resolution of their disseminated calcinosis evaluated at physical examination after 1 year of treatment with low-dose warfarin. The non-responding patient had larger and longer-standing calcinosis [37]. However, in another study of six patients with extensive and long-standing calcinosis (one with SSc) treated with low-dose warfarin for a mean of 14.6 months, five had clinical and radiological worsening of calcinosis [38]. In the Mayo Clinic study, of 19 patients with calcinosis and ACTD, four received warfarin for conditions other than calcinosis, without differences in response compared with the group that did not 
receive warfarin $[4 \bullet \bullet]$. There is a low risk for hemorrhages with warfarin, and rarely, it can cause skin necrosis.

\section{Minocycline}

This tetracycline antibiotic has anti-inflammatory and calcium-binding properties. Robertson et al. published a study of nine patients with lcSSc and calcinosis treated with 50 or $100 \mathrm{mg} /$ day of minocycline for a mean of 3.5 years. Eight patients who were able to tolerate the therapy experienced reduction in ulceration and inflammation associated with calcinosis, with a modest decrease in the size of deposits assessed clinically and radiographically. An unexpected effect was the darkening of the calcinosis from white/yellow to blue/black color. Two patients who discontinued the treatment temporarily had recurrence of calcinosis, so the authors recommended cyclic long-term use of minocycline (treatment for 4-8 weeks followed by discontinuation for 3-4 months). [39] Potential side effects of minocycline are skin pigmentation, dizziness, and rash.

\section{Colchicine}

As with minocycline, colchicine seems to be more effective in reducing the inflammation associated with calcinosis than the size of calcium deposits [28••]. Colchicine has anti-inflammatory effects by disrupting leukocyte chemotaxis and phagocytosis through inhibiting microtubule polymerization. Only a few reports of the use of colchicine in patients with SSc have been published [2•]. One patient with SSc and prepatellar calcinosis received $1 \mathrm{mg} /$ day of oral colchicine and had regression of the associated local inflammation and healing of associated skin ulcers after 2 months of follow-up [40]. Another patient with linear scleroderma and ulcerated cutaneous calcinosis was treated with colchicine $1 \mathrm{mg} /$ day, with healing of the ulcerations after 4 months [41]. In the Mayo Clinic study, three out of eight patients had positive response with colchicine, from which one reported complete resolution of calcium deposits. The authors proposed colchicine as a second choice for calcinosis treatment

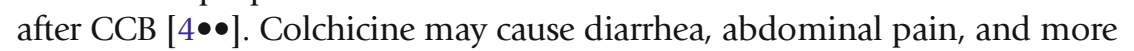
rarely, nerve or muscle damage.

\section{Ceftriaxone}

This third-generation cephalosporin is able to bind calcium ions and form insoluble calcium complexes [35]. There is one report of a patient with morphea and multiple calcinosis deposits who experienced significant regression of calcinosis lesions and no new lesions with ceftriaxone ( $2 \mathrm{~g} /$ day) intravenously for 20 days [42].

\section{Probenecid}

Probenecid is an uricosuric drug approved for treatment to prevent gout attacks. It increases renal phosphate clearance and therefore decreases the serum 
phosphate level, reducing the calcification process. Although not studied in SSc, one patient with juvenile DM and extensive calcinosis who was treated with probenecid up to $500 \mathrm{mg}$ three times daily showed clinical and radiographic improvement after 7 months [43]. It potentially may cause rash, diarrhea, and nephrolithiasis.

\section{Aluminum hydroxide}

Aluminum hydroxide also decreases serum phosphate levels by decreasing intestinal absorption. Aluminum hydroxide has been used successfully as a treatment for calcinosis in SLE and several DM patients, with softening and size reduction of calcinosis deposits [44, 45]. One case report of treatment with aluminum hydroxide $30 \mathrm{~mL}$ four times daily for calcinosis has been published in a SSc patient, showing good response [46]. The most common side effects of aluminum hydroxide are GI symptoms such as nausea, constipation, discoloration of feces, and abdominal pain. It should be used with caution in patients with renal failure because aluminum may accumulate causing severe phosphate depletion and secondary osteomalacia or osteoporosis.

\section{Intravenous immunoglobulins}

The use of intravenous immunoglobulins (IVIG) in the treatment of calcinosis is limited and has shown mixed results. Only one case report in SSc-associated calcinosis treated with IVIG has been published by Schanz et al. They reported that a patient with lcSSc and disabling calcinosis of the left index finger was free of symptoms after 5 months of IVIG [47]. The authors hypothesize that this effect was based on its anti-inflammatory properties, possibly related to suppression of activated macrophages. There is conflicting data on DM-associated calcinosis with positive $[48,49]$ and negative [50] results. Potential side effects are allergic and infusion reactions, headache, aseptic meningitis, and thrombosis.

\section{Biologic agents}

Given the potential role of inflammation and TNF- $\alpha$ in calcinosis, antiTNF agents may be useful in the treatment of calcinotic lesions. One case report of a patient with SSc-myositis overlap and refractory calcinosis treated with infliximab $3 \mathrm{mg} / \mathrm{kg}$ infused at 0,2 , and 6 weeks, and every 8 weeks thereafter, showed reduction in size of calcifications and no new deposits at 41 months in serial pelvic CT imaging [51•].

Rituximab, a chimeric anti-CD20 antibody, may be another promising therapy to treat calcinosis in patients with SSc. One lcSSc patient with extensive calcinotic lesions experienced reduction in size of these on physical examination, and her pain improved substantially after 1 year of treatment with two courses of rituximab (four weekly infusions of $375 \mathrm{mg} / \mathrm{m}^{2}$ each) 18 months apart [15•]. Another recent case report of a female with lcSSc using the same regimen of rituximab to treat interstitial lung disease and arthritis showed complete resolution of 
calcinosis in her hands after 7 months of the first infusion [52•]. A case series of 10 SSc patients treated with one or more cycles of rituximab (four weekly infusions of $375 \mathrm{mg} / \mathrm{m}^{2}$ ) for lung, cutaneous, or articular disease reported that three out of six patients who had calcinosis at baseline had clinical improvement as early as 6 months after the first cycle, which continued to improve through the end of the follow-up period (37 \pm 21 months, range 18-72 months) [53]. In contrast, Hurabielle et al. reported the case of a female SSc patient with X-ray evidence of calcinosis on her right wrist, who received two infusions of rituximab (1 g each) at a 2-week interval, and then every 6 months, for interstitial lung disease and arthritis. She subsequently developed extensive calcinosis on her wrist and left elbow [54].

\section{Emerging therapies}

Potential future medical therapies for calcinosis in SSc and other ACTD include more powerful vasodilatory therapies such as phosphodiesterase 5-inhibitors and prostacyclins. Preliminary observations in the Pulmonary Hypertension Assessment and Recognition of Outcomes in Scleroderma (PHAROS) registry have found that two patients with SScpulmonary arterial hypertension (PAH) and calcinosis treated with subcutaneous treprostinil for PAH simultaneously experienced approximately $50 \%$ radiographic improvement in their calcinosis lesions after 6 months of therapy (Shapiro et al., unpublished data). Other antiinflammatory and immunomodulatory agents such as calcineurin inhibitors, other anti-TNF agents, anakinra (IL-1 receptor inhibitor), or tocilizumab (monoclonal antibody to IL-6) may potentially have an effect on calcinosis. These treatments will need evaluation in prospective studies and randomized controlled trials.

\section{Interventional procedures}

\section{Carbon dioxide laser vaporization}

The carbon dioxide ( $\mathrm{CO}$ ) laser-tissue vaporization procedure is a bloodless technique that allows excellent visualization and vaporization of calcium deposits. Bottomley et al. treated six SSc patients with a total of 21 areas of symptomatic digital calcification of the fingers and found complete resolution of pain and function in 12, partial improvement in 5 , little improvement in 2, and recurrence of calcinosis in 2 after a median follow-up of 20 months [55]. In a more recent case report, six affected digits in a lcSSc patient received a single treatment with $\mathrm{CO}$ laser vaporization over 5 years, with complete healing and resolution of symptoms after 6 weeks [56].

\section{Extracorporeal shock wave lithotripsy}

Extracorporeal shock wave lithotripsy (ESWL) is a minimally invasive, safe, and well-tolerated technique that may offer effective remission of symptoms and 
healing of ulcerations related to calcinosis. Sparsa et al. described the case of a lcSSc patient with calcinosis and extensive secondary ulcerations that was successfully treated by ESWL [57]. One prospective study of nine patients (three with SSc) with progressive calcinosis found that after three ESWL sessions at 3week intervals, there was a reduction in the median area of calcinosis from 3.1 to $1.9 \mathrm{~cm}^{2}$. In addition, visual analog scale pain scores (range 0-10) decreased from 7 to 2 after 6 months [58].

\section{Surgical excision}

\section{Conclusions}

Surgical excision is treatment of choice for larger and deeper calcium deposits, especially when they are located over tendons, blood vessels, and nerves, whose integrity and function need to be preserved. [59] In the Mayo Clinic experience, all 11 patients who underwent surgical excision alone responded (eight with complete response), as well as 16 out of 17 patients who received medical and surgical therapy (14 with complete response). In contrast, only 7 of 19 patients treated with medical therapy alone had any response (one with complete response) $[4 \bullet \bullet]$. Potential risks of surgical excision are slow wound healing, which may lead to skin necrosis, infection, and decreased range of motion [60, 61]. Skin incision with drainage is the simplest procedure, but if this is not sufficient, partial removal can be obtained by curettage as proposed by Saddic et al. They reported excellent clinical outcomes, including decreased pain and short healing times, in one patient with lcSSc who underwent curettage of calcinosis on the tip of his left third finger [62]. An additional approach is a debulking procedure using a high-speed micro-burr to soften calcinosis. A retrospective study of nine SSc patients with calcinosis affecting the digits showed a high degree of patient satisfaction and lower disability scores (measured by Disabilities of the Arm, Shoulder, and Hand questionnaire and the Michigan Hand Questionnaire) with this method. However, no patients reported complete resolution of calcinosis, and seven patients had recurrence [63•]. Referral to a surgeon experienced in treating patients with SSc should be placed in cases of large, localized, and symptomatic calcinosis.

Calcinosis is a common problem affecting one quarter of patients with SSc. It most commonly affects the hands, particularly the fingers, and is related to inflammation and hypoxia. Common and potentially debilitating complications are local inflammation, ulceration, and infection. Although there is no universally effective treatment for calcinosis in patients with SSc, several pharmacological therapies has been proposed as effective, as monotherapy or in combination, including $\mathrm{CCB}$, colchicine, bisphosphonates, warfarin, ceftriaxone, minocycline, probenecid, aluminum hydroxide, IVIG, anti-TNF, and rituximab. Surgical removal of calcinosis remains the mainstay for treatment. Clinical trials using novel 
outcome measures are necessary to determine the efficacy of current and emerging treatments.

\section{Compliance with Ethical Standards}

Conflict of Interest

Antonia Valenzuela declares that she has no conflicts of interest. Lorinda Chung reports that she is on the Advisory Board for Gilead and the Data Monitoring Committee for Cytori, outside the submitted work.

Human and Animal Rights and Informed Consent

This article does not contain any studies with human or animal subjects performed by any of the authors.

\section{References and Recommended Reading}

Papers of particular interest, published recently, have been

highlighted as:

- Of importance

- Of major importance

1. Chander S, Gordon P. Soft tissue and subcutaneous calcification in connective tissue diseases. Curr Opin Rheumatol. 2012;24(2):158-64.

This review discusses the most relevant data about calcinosis in connective-tissue diseases with emphasis on the pathogenesis and its treatment.

2. Gutierrez Jr A, Wetter DA. Calcinosis cutis in autoimmune connective tissue diseases. Dermatol Ther. 2012;25(2):195-206.

This article review recommendations for the diagnosis and therapy of calcinosis cutis in patients with autoimmune connective tissue diseases.

3. Valenzuela A, Baron $\mathrm{M}$, the Canadian Scleroderma Research Group, Herrick A, Proudman S, Stevens W et al. Calcinosis is associated with digital ulcers and osteoporosis in patients with systemic sclerosis: a Scleroderma Clinical Trials Consortium Study. 14th Scleroderma Research Workshop August 1-5, 2015.; Cambridge, UK. 2015.

4.• Balin SJ, Wetter DA, Andersen LK, Davis MD. Calcinosis cutis occurring in association with autoimmune connective tissue disease: the Mayo Clinic experience with 78 patients, 1996-2009. Arch Dermatol. 2012;148(4):455-62.

This article analyzes the clinical features, treatments, and outcomes of ACTD patients with calcinosis cutis in the Mayo Clinic between years 1996-2009.

5. $\quad$ Shahi V, Wetter DA, Howe BM, Ringler MD, Davis MD. Plain radiography is effective for the detection of calcinosis cutis occurring in association with autoimmune connective tissue disease. $\mathrm{Br} J$ Dermatol.

2014;170(5):1073-9.
Retrospective study that described imaging findings and radiological patterns of calcinosis cutis in ACTD.

6. Avouac J, Mogavero G, Guerini H, Drape JL, Mathieu A, Kahan A, et al. Predictive factors of hand radiographic lesions in systemic sclerosis: a prospective study. Ann Rheum Dis. 2011;70(4):630-3.

7. Koutaissoff S, Vanthuyne M, Smith V, De Langhe E, Depresseux G, Westhovens R, et al. Hand radiological damage in systemic sclerosis: comparison with a control group and clinical and functional correlations. Semin Arthritis Rheum. 2011;40(5):455-60.

8. Johnstone EM, Hutchinson CE, Vail A, Chevance A, Herrick AL. Acro-osteolysis in systemic sclerosis is associated with digital ischaemia and severe calcinosis. Rheumatology (Oxford, England). 2012;51(12):2234-8.

Retrospective single-center study aimed to investigate the hypothesis that acro-osteolysis is associated with the severity of digital ischaemia and the presence of calcinosis.

9. Vayssairat M, Hidouche D, Abdoucheli-Baudot N, Gaitz JP. Clinical significance of subcutaneous calcinosis in patients with systemic sclerosis. Does diltiazem induce its regression? Ann Rheum Dis. 1998;57(4):252-4.

10. Steen VD, Ziegler GL, Rodnan GP, Medsger Jr TA. Clinical and laboratory associations of anticentromere antibody in patients with progressive systemic sclerosis. Arthritis Rheum. 1984;27(2):125-31.

11. D'Aoust J, Hudson M, Tatibouet S, Wick J, Mahler M, Baron $\mathrm{M}$, et al. Clinical and serologic correlates of antiPM/Scl antibodies in systemic sclerosis: a multicenter study of 763 patients. Arthritis Rheumatol (Hoboken, NJ). 2014;66(6):1608-15. 
12.• Li Q, Jiang Q, Uitto J. Ectopic mineralization disorders of the extracellular matrix of connective tissue: molecular genetics and pathomechanisms of aberrant calcification. Matrix Biol : J Int Soc Matrix Biol. 2014;33:23-8.

This overview discusses studies of ectopic heritable mineralization disorders manifesting with extensive connective tissue mineralization, with accompanying animal models.

13. Reiter N, El-Shabrawi L, Leinweber B, Berghold A, Aberer E. Calcinosis cutis: part I. Diagnostic pathway. J Am Acad Dermatol. 2011;65(1):1-12.

14. Walsh JS, Fairley JA. Calcifying disorders of the skin. J Am Acad Dermatol. 1995;33(5 Pt 1):693-706.

15. Daoussis D, Antonopoulos I, Liossis SN, Yiannopoulos G, Andonopoulos AP. Treatment of systemic sclerosisassociated calcinosis: a case report of rituximab-induced regression of CREST-related calcinosis and review of the literature. Semin Arthritis Rheum. 2012;41(6):822-9.

Case report of a SSc patient with calcinosis successfully treated with rituximab and extensive review of the literature.

16. Mukamel M, Horev G, Mimouni M. New insight into calcinosis of juvenile dermatomyositis: a study of composition and treatment. J Pediatr. 2001;138(5):763-6.

17. Davies CA, Jeziorska M, Freemont AJ, Herrick AL. The differential expression of VEGF, VEGFR-2, and GLUT-1 proteins in disease subtypes of systemic sclerosis. Hum Pathol. 2006;37(2):190-7.

18. Davies CA, Herrick AL, Cordingley L, Freemont AJ, Jeziorska M. Expression of advanced glycation end products and their receptor in skin from patients with systemic sclerosis with and without calcinosis. Rheumatology (Oxford, England). 2009;48(8):876-82.

19. Chung L, Valenzuela A, Fiorentino D, Stevens K, Li S, Harris J, et al. Validation of a novel radiographic scoring system for calcinosis affecting the hands of patients with systemic sclerosis. Arthritis Care Res. 2014. This article presents the development and validation of a novel radiographic scoring system for calcinosis affecting the hands of SSc patients for potential use in future clinical trials.

20. Freire V, Becce F, Feydy A, Guerini H, Campagna R, Allanore $\mathrm{Y}$, et al. MDCT imaging of calcinosis in systemic sclerosis. Clin Radiol. 2013;68(3):302-9.

This review provides an overview of the various appearances of calcinosis in SSc patients as visualized at MDCT.

21. Elhai M, Guerini H, Bazeli R, Avouac J, Freire V, Drape $\mathrm{JL}$, et al. Ultrasonographic hand features in systemic sclerosis and correlates with clinical, biologic, and radiographic findings. Arthritis Care Res. 2012;64(8):1244-9.

22. Freire V, Bazeli R, Elhai M, Campagna R, Pessis E, Avouac J, et al. Hand and wrist involvement in systemic sclerosis: US features. Radiology. 2013;269(3):824-30.

23. Hsu V, Bramwit M, Schlesinger N. Dual-energy computed tomography for the evaluation of calcinosis in systemic sclerosis. J Rheumatol. 2015;42(2):345-6.
This case report proposes DECT imaging as a useful imaging modality to assess SSc-calcinosis of the hands.

24. Hughes M, Freemont TJ, Denton J, Herrick AL. Infected calcinosis of the knee in limited cutaneous systemic sclerosis. J Rheumatol. 2012;39(10):2043-4.

25. Hazen PG, Walker AE, Carney JF, Stewart JJ. Cutaneous calcinosis of scleroderma. Successful treatment with intralesional adrenal steroids. Arch Dermatol. 1982;118(5):366-7.

26. Pando J, Nashel DJ. Clinical images: progressive calcifications and draining lesions following staphylococcal infection in a patient with limited scleroderma. Arthritis Rheum. 1998;41(2):373.

27. Bussone G, Berezne A, Mouthon L. [Infectious complications of systemic sclerosis]. Presse Med (Paris, France : 1983). 2009;38(2):291-302. Complications infectieuses de la sclerodermie systemique. fre.

28.• Dima A, Balanescu P, Baicus C. Pharmacological treatment in calcinosis cutis associated with connectivetissue diseases. Rom J Intern Med = Rev Roum Med Intern. 2014;52(2):55-67.

Extensive literature review of pharmacological treatment options for calcinosis in ACTD.

29. Palmieri GM, Sebes JI, Aelion JA, Moinuddin M, Ray MW, Wood GC, et al. Treatment of calcinosis with diltiazem. Arthritis Rheum. 1995;38(11):1646-54.

30. Dolan AL, Kassimos D, Gibson T, Kingsley GH. Diltiazem induces remission of calcinosis in scleroderma. Br J Rheumatol. 1995;34(6):576-8.

31. Farah MJ, Palmieri GM, Sebes JI, Cremer MA, Massie JD, Pinals RS. The effect of diltiazem on calcinosis in a patient with the CREST syndrome. Arthritis Rheum. 1990;33(8):1287-93.

32. Metzger AL, Singer FR, Bluestone R, Pearson CM. Failure of disodium etidronate in calcinosis due to dermatomyositis and scleroderma. N Engl J Med. 1974;291(24):1294-6.

33. Rabens SF, Bethune JE. Disodium etidronate therapy for dystrophic cutaneous calcification. Arch Dermatol. 1975;111(3):357-61.

34. Fujii N, Hamano T, Isaka Y, Ito T, Imai E. Risedronate: a possible treatment for extraosseous calcification. Clin Calcium. 2005;15(1):75-8. discussion 8-9.

35. Reiter N, El-Shabrawi L, Leinweber B, Berghold A, Aberer E. Calcinosis cutis: part II. Treatment options. J Am Acad Dermatol. 2011;65(1):15-22. quiz 3-4.

36. Berger RG, Featherstone GL, Raasch RH, McCartney WH, Hadler NM. Treatment of calcinosis universalis with low-dose warfarin. The American journal of medicine. 1987;83(1):72-6.

37. Cukierman T, Elinav E, Korem M, Chajek-Shaul T. Low dose warfarin treatment for calcinosis in patients with systemic sclerosis. Ann Rheum Dis.

2004;63(10):1341-3.

38. Lassoued K, Saiag P, Anglade MC, Roujeau JC, Touraine RL. Failure of warfarin in treatment of calcinosis universalis. Am J Med. 1988;84(4):795-6. 
39. Robertson LP, Marshall RW, Hickling P. Treatment of cutaneous calcinosis in limited systemic sclerosis with minocycline. Ann Rheum Dis. 2003;62(3):267-9.

40. Fuchs D, Fruchter L, Fishel B, Holtzman M, Yaron M. Colchicine suppression of local inflammation due to calcinosis in dermatomyositis and progressive systemic sclerosis. Clin Rheumatol. 1986;5(4):527-30.

41. Vereecken P, Stallenberg B, Tas S, de Dobbeleer G, Heenen M. Ulcerated dystrophic calcinosis cutis secondary to localised linear scleroderma. Int J Clin Pract. 1998;52(8):593-4.

42. Reiter N, El-Shabrawi L, Leinweber B, Aberer E. Subcutaneous morphea with dystrophic calcification with response to ceftriaxone treatment. J Am Acad Dermatol. 2010;63(2):e53-5.

43. Eddy MC, Leelawattana R, McAlister WH, Whyte MP. Calcinosis universalis complicating juvenile dermatomyositis: resolution during probenecid therapy. J Clin Endocrinol Metab. 1997;82(11):3536-42.

44. Park YM, Lee SJ, Kang H, Cho SH. Large subcutaneous calcification in systemic lupus erythematosus: treatment with oral aluminum hydroxide administration followed by surgical excision. J Korean Med Sci. 1999;14(5):589-92.

45. Boulman N, Slobodin G, Rozenbaum M, Rosner I. Calcinosis in rheumatic diseases. Semin Arthritis Rheum. 2005;34(6):805-12.

46. Hudson PM, Jones PE, Robinson TW, Dent CE. Extensive calcinosis with minimal scleroderma: treatment of ectopic calcification with aluminum hydroxide. Proc R Soc Med. 1974;67(11):1166-8.

47. Schanz S, Ulmer A, Fierlbeck G. Response of dystrophic calcification to intravenous immunoglobulin. Arch Dermatol. 2008;144(5):585-7.

48. Penate Y, Guillermo N, Melwani P, Martel R, Hernandez-Machin B, Borrego L. Calcinosis cutis associated with amyopathic dermatomyositis: response to intravenous immunoglobulin. J Am Acad Dermatol. 2009;60(6):1076-7.

49. Touimy M, Janani S, Rachidi W, Etaouil N, Mkinsi O. Calcinosis universalis complicating juvenile dermatomyositis: improvement after intravenous immunoglobulin therapy. Joint Bone Spine : Rev Rhum. 2013;80(1):108-9.

50. Kalajian AH, Perryman JH, Callen JP. Intravenous immunoglobulin therapy for dystrophic calcinosis cutis: unreliable in our hands. Arch Dermatol. 2009;145(3):334. author reply 5.

51. Tosounidou S, MacDonald H, Situnayake D. Successful treatment of calcinosis with infliximab in a patient with systemic sclerosis/myositis overlap syndrome. Rheumatology (Oxford). 2014;53(5):960-1.

Case report of a patient with severe calcinosis that responded to Infliximab.

52.• de Paula DR, Klem FB, Lorencetti PG, Muller C, Azevedo VF. Rituximab-induced regression of CRESTrelated calcinosis. Clin Rheumatol. 2013;32(2):281-3.

Case report of a SSc patient with calcinosis successfully treated with Rituximab.

53. Giuggioli D, Lumetti F, Colaci M, Fallahi P, Antonelli A, Ferri C. Rituximab in the treatment of patients with systemic sclerosis. Our experience and review of the literature. Autoimmun Rev. 2015;14(11):1072-8.

54. Hurabielle C, Allanore Y, Kahan A, Avouac J. Flare of calcinosis despite rituximab therapy. Semin Arthritis Rheum. 2014;44(2):e5-6.

55. Bottomley WW, Goodfield MJ, Sheehan-Dare RA. Digital calcification in systemic sclerosis: effective treatment with good tissue preservation using the carbon dioxide laser. Br J Dermatol. 1996;135(2):302-4.

56. Chamberlain AJ, Walker NP. Successful palliation and significant remission of cutaneous calcinosis in CREST syndrome with carbon dioxide laser. Dermatol Surg : Off Publ Am Soc Dermatol Surg. 2003;29(9):968-70.

57. Sparsa A, Lesaux N, Kessler E, Bonnetblanc JM, Blaise S, Lebrun-Ly $\mathrm{V}$, et al. Treatment of cutaneous calcinosis in CREST syndrome by extracorporeal shock wave lithotripsy. J Am Acad Dermatol. 2005;53(5 Suppl 1):S263-5.

58. Sultan-Bichat N, Menard J, Perceau G, Staerman F, Bernard P, Reguiai Z. Treatment of calcinosis cutis by extracorporeal shock-wave lithotripsy. J Am Acad Dermatol. 2012;66(3):424-9.

59. Merlino G, Germano S, Carlucci S. Surgical management of digital calcinosis in CREST syndrome. Aesthet Plast Surg. 2013;37(6):1214-9.

60. Bogoch ER, Gross DK. Surgery of the hand in patients with systemic sclerosis: outcomes and considerations. J Rheumatol. 2005;32(4):642-8.

61. Yang JH, Kim JW, Park HS, Jang SJ, Choi JC. Calcinosis cutis of the fingertip associated with Raynaud's phenomenon. J Dermatol. 2006;33(12):884-6.

62. Saddic N, Miller JJ, Miller 3rd OF, Clarke JT. Surgical debridement of painful fingertip calcinosis cutis in CREST syndrome. Arch Dermatol. 2009;145(2):212-3.

63. Lapner MA, Goetz TJ. High-speed burr debulking of digital calcinosis cutis in scleroderma patients. J Hand Surg. 2014;39(3):503-10.

A retrospective analysis of 9 consecutively enrolled SSc patients with calcinosis who underwent surgery using a high-speed burr. 